\title{
Central obesity, not BMI explains cardio-metabolic risks among university employees, Ethiopia - a cross- sectional study
}

\section{Balamurugan Janakiraman ( $\sim$ bala77physio@gmail.com )}

Department of Physiotherapy, School of Medicine, College of Medicine and Health Sciences, University of

Gondar and Gondar University specialized comprehensive hospital, Ethiopia https://orcid.org/0000-0003-38669351

\section{Solomen Mekonnen Abebe}

University of Gondar College of Medicine and Health Sciences

Mulugeta Bayisa Chala

Queens university

\section{Solomon Fasika Demissie}

University of Gondar College of Medicine and Health Sciences

\section{Research article}

Keywords: Diabetes mellitus, Hypertension, pre-hypertension, pre-diabetes, Ethiopia

Posted Date: July 3rd, 2019

DOI: https://doi.org/10.21203/rs.2.10882/v1

License: (c) (1) This work is licensed under a Creative Commons Attribution 4.0 International License. Read Full License 


\section{Abstract}

Background: Evidence suggests that the middle and low-income countries such as Ethiopia are facing the growing epidemic of both communicable and non-communicable diseases creating burden on the healthcare system. The increasing prevalence is attributed to sedentarism, lifestyle changes and the presence of other cardio-metabolic risk factors. Therefore this study was designed to assess the prevalence and association of overweight, obesity, and cardio metabolic risks and to explore if there was any agreement among the anthropometric measurements among the academic employees of the University of Gondar, Ethiopia. Methods: An institutional based crosssectional study was conducted using the WHO stepwise approach and recommendations on 381 academic staff of the university. In addition, physical measurements such as weight, height, waist and hip circumferences, and biochemical measures such as blood pressure and fasting blood glucose level (peripheral blood samples by finger puncture) were measured using standardized tools. Result: The mean age of the participants was 33.5 years. The prevalence of obesity among the study participants defined by body mass index, waist circumference, waist height ratio and waist hip ratio was $13.1 \%, 33.6 \%, 51.9 \%$ and $58.5 \%$ respectively. The prevalence of diabetes was $4.7 \%$ among which $1.3 \%$ was not diagnosed prior to this study. About $53(13.9 \%)$ of the study sample were found to be hypertensive (6.3\% known versus $297.6 \%$ newly diagnosed). Among the participants $39.4 \%$ and $23.4 \%$ were found to be pre hypertensive and pre diabetic respectively. WC was significantly associated with HTN (AOR = 5.14; $2.50,9.72)$, pre-DM $(A O R=4.03 ; 2.974,5.96), D M(A O R=3.29 ; 1.09,6.01)$. In addition, WHtR was significantly associated with Pre-HTN (AOR = 2.69; 1.49, 4.58), HTN (AOR = 2.06; 1.01, 6.31), and DM (AOR = 1.85; .76, 4.32). Conclusion: This study results revealed the variable prevalence between general obesity and the anthropometric indices (IDF cutoff) defining central obesity; WC, WHtR, and WHR among the participants. The result of this study suggests that the constructs of central obesity, not BMI has to be used to screen risks of cardio-metabolic risks among Ethiopians. Keywords: Diabetes mellitus, Hypertension, pre-hypertension, pre-diabetes, Ethiopia

\section{Background}

The increase in the global prevalence of non-communicable diseases in the past four decades in high-income countries is well documented (1-3). There is evidence to suggest that low-income countries face the triple burden of undernourishment, communicable and non-communicable diseases attributed to low socio-economic status, lifestyle and nutrition changes (4-6). In sub-Saharan Africa (SSA), about $69 \%$ of mortality is caused by infectious diseases, while non-communicable diseases (NCDs) contribute around one-fourth of the deaths $(7,8)$. However, due to the ongoing epidemiological transition in these countries, there is a projection that death due to noncommunicable diseases is estimated to surpass death from infectious diseases in the year $2030(9,10)$.

Ethiopia is among the countries in the sub-Saharan region that is facing an increasing burden related to noncommunicable diseases. For instance, in previous Ethiopian studies, the prevalence of metabolic syndrome (Mets) and diabetes among the working population was reported as $14 \%$ and $6.5 \%$ respectively, while the prevalence of high blood pressure among these population ranges from 19.6\%-30.3\% (11-13). The international diabetic federation (IDF) in its 2014 report estimated the number of people living with diabetes to be 4.9 million and about 2.9 million people living with impaired blood glucose in Ethiopia. In addition, the report also estimated that the prevalence of undiagnosed diabetes to be about 1.4 million being higher in urban than rural population $(14,15)$. Moreover, among urban dwellers in Ethiopia, about $64.8 \%$ of hypertensive subjects and $53.4 \%$ of diabetic subjects were estimated to be undiagnosed $(16,17)$. 
Previous regional studies used IDF criteria to estimate cardio metabolic risks and association of anthropometric indices among bank workers, school teachers, policemen, and other general population (18-20). The IDF recommends Asian and SSA to use the driven cut off point to define obesity which is a known indicator and predictor for cardio metabolic risks (20). As a result, many studies in Ethiopia used the recommended cut off point to define obesity. Though it is recommended to use more reliable population specific anthropometric cut off measures and it is well known that slender body framed Ethiopian and some Asian countries still use international or European anthropometric cut off values to identify cardio-metabolic risks $(21,22)$. Hence, it is a high time for Ethiopia to initiate small and/ or large scale high risk approaches for screening NCDs in susceptible populations using simple and sensitive screening tools. Anthropometric indices are simple and effective indicators of general and central adiposity in identifying cardio-metabolic risks in the community and institutional populations in lowincome countries $(23,24)$.

Evidence substantiates the presence of correlation between sedentism and the increased chances of cardiometabolic risks among different population (25-27). Since University academic employees are more likely at risk of sedentism, occupational status, income, and other lifestyle changes, it is crucial to study cardio-metabolic risks and its associated factors among this population.. In Ethiopia, population-based data on the prevalence of diabetes; IFG and hypertension are scant unlike elsewhere, where these data across various occupational groups is recent interest (27-29). Current knowledge of cardio-metabolic risks in Ethiopia is mostly based on sporadic, convenience based, and hospital data from patients who present with NCDs. Considering the devastating effects of cardio-metabolic health problems on individuals living with chronic illnesses and the country at large, there is an urgent need and impartial attention of exploring cardio-metabolic health problems and its underlying risk factors in Ethiopia. Therefore, the aim of this study was to assess the prevalence of general obesity and central obesity and the association of these anthropometric indices with cardio-metabolic risks such as hypertension, prehypertension, impaired fasting glucose, and diabetes among academic employees in Northwest Ethiopia.

\section{Methods}

\section{Study design and subjects}

This institutional based cross-sectional study was conducted on 381 academic staff working at the University of Gondar, Gondar, Ethiopia. The University of Gondar is one of the oldest and highest educational institutions in Ethiopia located at $750 \mathrm{~km}$ north to capital city Addis Ababa. A total of 1387 Ethiopian academic staffs (1221

male, 166 female) who were working as permanent staff were considered as the study population. The study was conducted from November 2017 to January 2018.

The sample size was determined using Epi info version 7.0 (Centers for Disease Control and Prevention, USA). A two population proportion formula was used to calculate the desired sample size based on the previous study (25) with obesity in hypertensive and obesity in normotensive subjects as $45 \%$ and $30 \%$ respectively with an odds ratio of 1.91 . A power of $80 \%$ to detect real association of exposure variable and $95 \%$ level of confidence was used. The derived sample size was $n=390$, accounting for estimated refusal or non-response rate of $10 \%$ the required sample size was $n=429$. Obesity with DM and hypertension was taken from various regional studies. Finally, hypertension with the highest sample size was chosen.

Among the 1387 permanent academic staffs list secured from UOG, human resource department 429 questionnaires were distributed proportionately and randomly selected staffs in this survey. Socio-demographic, 
anthropometric indices, and cardio-metabolic risk factor data of recruited staffs were used in this study. About 62 Expatriate staffs, 5 subjects with abdominal surgeries within previous 3 months, 9 pregnant women and recent partitions were excluded.

\section{Data collection}

Data were collected by 8 nurses and 2 lab technicians. Two days of intensive training was given to the data collectors by BJ on the data collection procedures. The English version of WHO STEPS wise approach for surveillance of chronic Non-communicable Diseases Risk factor, version 4) (30) was used for data collection in this survey. The stepwise questionnaire risk factor assessment; Step 1 (interview questions), step 2 (physical measurements) and step 3 (biochemical measurement) were used. Procedure in this survey included completing the questionnaire, anthropometric measurement, measurement of blood pressure, and fasting blood glucose measurement.Weight was measured to the nearest $0.1 \mathrm{~kg}$ in light indoor clothing and bare feet or with socks. Height was measured using a wall standiometer to the nearest $0.1 \mathrm{~cm}$ with the participants standing erect posture, without shoes. Waist circumference was measured by placing a plastic tape to the nearest $0.1 \mathrm{~cm}$, horizontally midway between the $12^{\text {th }}$ rib and iliac crest on the mid-axillary line, using a stretch-resistant tape. Hip circumference was measured at the level of the greater trochanters with the tape parallel to the floor. Blood pressure (digital Omron, HEM-7111) was measured, according to WHO guidelines participant in sitting position rested for 10 minutes and 3 consecutive measurements at the interval of 3 min each. Portable glucometer (one touch, USA) and finger prick in the middle finger was used to measure fasting blood glucose. Self-reported current use of anti-hypertensive drugs and/or antidiabetic drugs was recorded.

\section{Definition of obesity and cardio-metabolic risks}

The definition criteria's were based on the International Diabetic Federation (IDF), WHO/International Society of Hypertension guidelines and American Diabetic Association (ADA) (31). General obesity was defined as BMI $\geq 25$ $\mathrm{kg} / \mathrm{m}^{2}$, central obesity was defined using Europid values; waist circumference (WC) of $\geq 94 \mathrm{~cm}$ (men), $\geq 80 \mathrm{~cm}$ (women), waist-height ratio (WHtR) of $\geq 0.50$ and waist-hip ratio (WHR) of $\geq 0.90$ (men), $\geq 0.85$ (women). The cardio-metabolic risk was defined as; Pre-diabetes (Pre-DM) was diagnosed if the FBG value was $\geq 100 \mathrm{mg} / \mathrm{dL}$ to $\leq 120 \mathrm{mg} / \mathrm{dL}$. Diabetes was diagnosed if FBG value was $>120 \mathrm{mg} / \mathrm{dl}$, self-reported Type Il diabetes mellitus, or diabetes medication. Pre-hypertension (Pre-HTN) was diagnosed if systolic blood pressure (SBP) $>120$ to $<140$ $\mathrm{mmHg}$ and/or diastolic blood pressure $>80$ to $<90 \mathrm{mmHg}$. Hypertension (HTN) was defined as SBP $\geq 140 \mathrm{mmHg}$ and/or DBP $\geq 90 \mathrm{~mm} \mathrm{Hg}$.

Ethical considerations

This study was approved by the School of Medicine Research and Ethical Review Board, University of Gondar (Ref/RPC312014). A detailed orientation of the survey objectives, procedures, possible outcomes and safety precaution in needle prick were explained prior to the signing of the informed consent form. Referral forms were used in case of abnormal biochemical findings for medical consultation and counseling in UOGH.

\section{Statistical analysis}


Data were coded and entered in Epi info software version 7.0 and exported to IBM Statistical Package for Social Sciences (SPSS) version 24 for Windows for statistical analysis. Mean and percentage with $95 \% \mathrm{Cl}$ adjusted for age was used to describe the distributions of socio-demographic characteristics, anthropometric measures and cardio-metabolic of the study population by cross-tabulation and independent t-test across gender. Pearson's chisquare was used to evaluate the difference between a categorical variable and age-adjusted one-way ANOVA was used to compare continuous variables. Pearson's correlation test was done to measure the association between anthropometric measures (BMI, WC, WHtR \& WHR), age, and cardio-metabolic risk variables (FBG, SBP, DBP). Age controlled bivariate analyses were conducted with the dependent variables (FBG, SBP, DBP) and independent variables that were found statistically significant were included in multivariate analysis. When clear subgroups seemed present in the data, significance testing (Pearson $\chi^{2}$ ) and, if appropriately sized subgroups per category remained, logistic regression was performed. The prevalence estimates for obesity defined by BMI, WC, WHtR, and WHR was determined separately. In all cases p-value $<0.05$ at $95 \%$ confidence interval was considered statistically significant.

\section{Results}

A total of 429 academic employees were approached for consent, out of which 381 employees (330 male, 51 females) consented and completed questionnaire, physical measurements, and biochemical measurements. The response rate was $89 \%$ and this is $97.6 \%$ of the power calculated sample size $(n=390)$. The mean age (in years), height $(\mathrm{cm})$, and weight $(\mathrm{kg})$ of the total participants were $34.33,164.15$ and 64.8 respectively with significant difference between gender. Majority of the participants (64.8\%) were below the age of 35 years and 339 (88.97\%) participants of the total sample were less than 45 years old.About73\% had postgraduate education level and no significant difference in educational level between genders. Among the participants, $6.3 \%$ and $7.6 \%$ were known HTN and newly diagnosed HTN, while $2.9 \%$ and $1.6 \%$ were known DM and newly diagnosed DM respectively. About 15 (3.9\%) participants had concurrent HTN and DM (Table 1). A gender wise statistically significant difference was observed between age, height, weight, and all anthropometric measures. Majority of the participants $(n=239,62.7 \%)$ were diagnosed either or both prehypertension and pre-diabetes.

The age-adjusted mean of overall BMI was $23.4 \mathrm{~kg} / \mathrm{m}^{2}$ and $24.8 \mathrm{~kg} / \mathrm{m}^{2}$ for men and women respectively. Agestandardized prevalence of pre-obesity in men (23.6\%), and women (23.5\%) and the prevalence of obesity are; men (3.3\%) and women (9.8\%). Mean BMI and the prevalence of pre-obesity or overweight and obesity by age group are shown in Table 2.

Mean of WC, WHtR, WHR and the prevalence of central obesity are shown in Table 3. The age-adjusted mean of overall WC, WHtR, and WHR for men were $88.2 \mathrm{~cm}, 0.52$, and 0.93 respectively. The age-adjusted mean of overall WC, WHtR, and WHR for women were $81.9 \mathrm{~cm}, 0.51$, and 0.90 respectively. Age-standardized prevalence of central obesity based on WC, WHtR, and WHR among men was 31.2\%, 53.3\%, and 58\% respectively. Age-standardized prevalence of central obesity based on WC, WHtR, and WHR among women was 49\%, 43.1\%, and $56.9 \%$ respectively. Among 275 participants with normal BMI, more than half ( $n=154(56 \%)$ ) were identified as centrally obese by WC, WHtR, and WHR.. Moreover, among participants with normal BMI, 96 (34.9\%), 26 (9.5\%), 48 (17.5\%), and $13(4.7 \%)$ were diagnosed and/or self-reported to have pre-HTN, HTN, pre-DM, and DM respectively. Only diabetes mellitus had no statistically significant difference among BMI category (Appendix file 1). 
Gender wise occurrence and mean of cardio-metabolic risks in both general obesity by BMI and central obesity by WC, WHtR, and WHR are shown in Table 4. Higher rate of pre-HTN and HTN in women was observed in central obesity groups whereas in men both general and central obesity groups showed close to similar occurrence. Higher rate of pre-DM was observed in central obesity group defined by WC in both men and women $58.3 \%$ and $64 \%$ respectively.

Among men, a significant positive correlation was seen between BMI, WC, WHtR, and WHR with SBP, DBP, and FBG. Among women, BMI showed a poor correlation with all cardio-metabolic risks. Pearson's correlation for the association between cardio-metabolic factors and anthropometric measure and age for both genders are shown in Table 5. In addition, all central obesity measure showed a significant positive correlation with cardio-metabolic risks except for WHtR and WHR with DBP which were non-significant.

The overall age-adjusted odds ratio of pre-HTN, HTN, pre-DM and DM for general obesity by BMI and central obesity defined by WC, WHtR, and WHR are shown in Table 6. WC was significantly associated and was the most sensitive for HTN (OR $5.14 p<0.001)$, pre-DM (OR $4.03 p<0.001)$ and diabetes (OR $3.29 p<0.02)$. WHtR was significantly associated with pre-HTN (OR 2.690), HTN (OR 2.066) and diabetes (OR 1.855). However, BMI and WHR were found not to be significantly associated with the cardio-metabolic risks included in the multivariate and bivariate regression model respectively.

\section{Discussion}

This study is unique in investigating the association between anthropometric measures which includes central and general obesity and cardio-metabolic risk factors such as Diabetes Mellitus and hypertension among the university academic employees in Ethiopia. This study results revealed variable prevalence between general obesity (27.8\%) and the anthropometric indices (IDF cutoff) defining central obesity; WC, WHtR and WHR was $33.6 \%, 52 \%$, and $58.5 \%$ respectively among the participants. In the current study more than half of all adults with excess body fat defined by WC, WHtR, and WHR were defined as non-obese according to BMI, which shows the possible bias associated with the use of BMI and underestimates of obesity and higher sensitivity of measures of central obesity in the study population.

With a higher prevalence of central obesity among the study participants and its association with pre-diabetes, diabetes, pre-hypertension, and hypertension explains that these comorbid conditions are reaching epidemic proportion in Ethiopia. Moreover, it is surprising to observe newly diagnosed diabetes (1.3\%) and hypertension (7.6\%) among the study samples given these population attained higher literacy level. This study also found that measures of central obesity defined by WC, and WHtR but not general obesity were strongly associated with cardio-metabolic risks in men and women. Though, the prevalence of WC was lower among measures of central obesity it showed the strongest association with HTN, pre-DM and DM while WHtR showed association with preHTN, HTN, and DM in our study participants. This is very unlike the findings reported elsewhere, while the difference could be explained by the uniqueness of the stature of Ethiopians (32).

Our study revealed that there is a high prevalence of pre-obesity among male $(29.4 \%)$ and female $(24.8 \%)$ using BMI measurement. To the contrary, the prevalence of obesity among men and women was $5.4 \%$ and $11.5 \%$ respectively. This is rather an intriguing finding and reasons might be that the majority of the study participants were younger than 35 years old and may eventually become obese if not intervened. 
The overall prevalence of overweight in the current study was $27.1 \%$, which is much higher than a pooled prevalence of overweight of $15.9 \%$ reported in Demographic and Health Survey (DHS) of 32 Sub-Saharan African countries, ranging from 5.6\% in Madagascar and 27.7\% in Swaziland (33). However, the prevalence of obesity defined by BMI in this study is within the range reported by the DHS study. According to $2016 \mathrm{WHO}$ report, the estimated prevalence of overweight or pre-obesity was 39\% among men and $40 \%$ among women, while the estimated prevalence of obesity was $11 \%$ among men and $15 \%$ among women, which is much lower than the figures reported in this study (34). Regardless, the trending of the prevalence of obesity in Ethiopia as reported by previous study (35), including this study requires attention. More interestingly, the obesity defined based on WC, WHtR and WHR were highly prevalent than defined by BMI. And it is worth to note that slender body framed Ethiopians have higher body fat at relatively low body mass index compared to study samples from other countries (32). Systematic reviews of a large amount of high-quality and consistent evidence show that the use of BMI to define obesity (the degree of excess body fat) might be highly specific, but has low to moderate sensitivity when compared with obesity defined by WC, WHtR, and WHR $(36,37)$.

The overall prevalence of hypertension and diabetes among the participants were $13.9 \%$ and $4.5 \%$ respectively. Among which a large proportion of them were undiagnosed and thus untreated. In addition, this study also found that $39.4 \%$ of the participants were pre-hypertensive and based on IDF criteria $23.4 \%$ were pre-diabetic which implies that these people are at risk of developing HTN and diabetes in the future if not intervened early. The prevalence of hypertension reported in this study involving healthy population is significantly higher than that of earlier reports in Ethiopia which was $7.1 \%$ and $1.8 \%(38,39)$ of two and three decades ago respectively which is suggestive of the ongoing salient rise in this country. The reasons for higher undiagnosed cardio-metabolic risks might be due to low health seeking behavior among Ethiopians and if this is the case among the educated study population, it might be a major concern among the larger illiterate Ethiopian population.

However, the prevalence of hypertension reported in this study is lower than other community-based studies in Ethiopia which is $28.3 \%$ (40) and $30 \%$ (41). The prevalence of diabetes in the current study is consistent with the growing body of regional evidence particularly urban dwellers $(42,43)$. Unlike many other regional studies $(40,43-$ $45)$, the odds of likely cardio-metabolic risks in this current study population is only explained by measures of central obesity and not by body mass index. Moreover, surprisingly WHtR which is proposed (46) as a good indicator of abdominal obesity (AO) and a better predictor of cardio-metabolic risk had lesser odds of likely cardiometabolic risks than WC in our study participants. This might be due to over estimation because WC does not take height (risk of tall) into consideration while defining AO and unique morphology of Ethiopians. About $91 \%$ of the current study samples were aged between 25 and 45 years and hence, higher prevalence of prehypertension and impaired fasting glucose risks among them based on central obesity (WC and WHtR) as indicated in this study should stand as an alert for Ethiopia.

Although there is variability of the prevalence of pre-diabetes in different literature, our finding suggests that 23.4 $\%$ of our study samples are pre-diabetic. This figure is slightly higher than a cross-sectional study conducted in Kenya $18 \%$ and $8.6 \%$ reported by a population study conducted in Uganda $(47,48)$. Likewise, our finding indicated a significantly higher prevalence of pre-hypertension among our samples when compared to a report from Iran $33.7 \%$ (49), while it is lower than what is reported in a Nigerian study $45.5 \%$ (50). This variability in the prevalence of pre-hypertension and pre-diabetes among different literature could be attributed to the population characteristics in the studies. Regardless, the finding from our study suggests that the necessity of designing health promotional activities which promote early health screening of cardio-metabolic risks such as diabetes and 
hypertension. In addition, since the majority of patients with diabetes and hypertension would undergo a long time of pre-diabetes and pre-hypertensive duration, it is essential to design target interventions to either reverse or slow down the progression of these conditions before it becomes full-blown diabetes or hypertension.

This study has reported a well-powered insight into the prevalence of self-reported and measured hypertension and diabetes (impaired fasting glucose) and its relationship with anthropometric indices among urban-dwelling university teachers. In addition, this study also reported on the prevalence of measurement based prehypertension and pre-diabetes unlike the previous studies done in Ethiopia. For the benefits of future research few limitations are to be addressed. Since females are less represented in this study as a result of low proportion of female academic employees at the University of Gondar, the results of this study should be interpreted with caution especially when policy decisions are made. Definition of measured DM and pre-DM is based on only impaired fasting glucose level and post-prandial glucose level was not measured. The results of this study must be interpreted with caution; the study samples were academic employees of the University of Gondar and thus the findings cannot be generalized to all Ethiopians. Due to the cross-sectional nature of the study, temporal relations could not be established between measure obesity and the cardio-metabolic risks. Its cross-sectional design was also limited in evaluating cause-and-effect associations. Despite these limitations, the findings from this study may strengthen the existing body of knowledge and also fill the gaps of the already limited data on cardiometabolic risks in Sub-Saharan Africa and in the study area.

\section{Conclusion And Recommendation}

Despite the fact that this study adapted Europid cutoff to define central obesity, the findings of this study can alarm the epidemics of non-communicable diseases and obviate the need for Ethiopian cutoff to define central obesity. The expected rapid escalation of cardio-metabolic risks cannot be ruled out, particularly in Ethiopia, as it can destabilize economy which is still reeling from infectious diseases. However, it should be understood that anthropometric Europid cut-offs for detecting central obesity may not be appropriate for Ethiopians.

Previous studies outlined that cardio-metabolic risk factors disproportionately affect the less educated and poorer segment of the society which has been attributed to health-seeking behaviors $(11,39,42)$. In contrast, a systematic review of studies from Sub-Saharan African countries (51) indicated that increased wealth and better education was associated with an increased risk of diabetes in both male and female participants. Given this contrasting suggestion from literature and the high number of pre-hypertension and pre-diabetes among university staff in our study, we recommend future researchers to conduct comparative studies on the prevalence and risk factors of cardio-metabolic risk factors between the less educated, economically disadvantaged rural and the highly educated urban populations in Ethiopia. We also suggest that appropriate screen methods are put in place to mitigate the public health crisis that may arise from undiagnosed hypertension and diabetes.

\section{Abbreviations}

AO: Abdominal obesity; AOR: Adjusted odds ratio; BMI: Body mass index; Cl: Confidence interval; DHS: Demographic Health Survey; DBP: Diastolic blood pressure; EDHS: Ethiopian Demographic Health Survey; IFG: Impaired fasting glucose; IDF: International Diabetes Federation; NCDs: Non Communicable Diseases; SBP: Systolic blood pressure; WC: Waist circumference; WHO: World Health Organization; WHtR: Waist Height Ratio; WHR: Waist Hip Ratio 


\section{Declarations}

\section{Ethical Approval and consent to participate}

Ethical clearance was secured from the ethical review committee of the College of Medicine and Health Sciences, Univeristy of Gondar, Ethiopia. [Reference number of ethical approval: Ref/RPC312014]. Written consent was obtained from all participants prior to the participation in the study.

\section{Consent for publication}

Not applicable

\section{Availability of data and material}

Since this is funded work the raw data is the property of the University of Gondar and the data that are confidential cannot be made publicly available in order to protect participant's privacy. Data may be available to interested researchers upon formal request from the corresponding author (Balamurugan Janakiraman: bala77physio@gmail.com)

\section{Competing interests}

The authors declare that they have no competing interests and all authors also declare that they have no conflict of interest resulting from this work, not in financial or personal relationships.

\section{Funding}

This study was fully funded by University of Gondar scientific research grant number (08/202/06 CMHS, UOG). The funder has no role in the design of the study and collection, analysis, and interpretation of data and in writing the manuscript.

\section{Authors' contributions}

BJ brought the original idea, was involved in the proposal writing, defending and securing grant, designed the study, and participated in all the implementation stages of the project. BJ also analyzed data and wrote the initial version of the manuscript. BJ, SMA, and MB participated in the conception of the original idea and were involved in proposal writing. BJ, SMA, MB and SFD were involved with data analysis. BJ checked and reran data analyses and extensively rewrote the manuscript prior to submission. BJ, MB and SMA critically revised the manuscript for important intellectual content. All the authors read and approved the final version of the manuscript.

\section{Acknowledgements}


We appreciate University of Gondar and University of Gondar referral hospital for financial support of this study. We also extend our hearted thanks to study participants and data collectors.

\section{References}

1. Kromeyer-Hauschild K, Moss A, Wabitsch M. Global BMI Trends. Oxf Handb Econ Hum Biol. 2016;296.

2. Roglic G. WHO Global report on diabetes: A summary. Int J Noncommunicable Dis. 2016;1(1):3.

3. Balamurugan J, Hariharasudhan R. Physical Therapy Interventions are Beyond Adjunct Care in Improving Quality of Life and Alleviating Pain Related to Cancer and its Treatment: Perspectives and Confronts. J Cell Sci Ther. 2015;6(6):1.

4. Steyn NP, Mchiza ZJ. Obesity and the nutrition transition in Sub-Saharan Africa. Ann N Y Acad Sci. 2014;1311(1):88-101.

5. Ford ND, Patel SA, Narayan KV. Obesity in low-and middle-income countries: burden, drivers, and emerging challenges. Annu Rev Public Health. 2017;38:145-64.

6. Vorster HE, Bourne LT. The Nutrition Transition in Developing Countries. Community Nutr Dev Ctries. $2016 ; 54$.

7. Belachew T. Are we ready for the rising silent epidemic of metabolic syndrome and chronic noncommunicable disease in Ethiopia? Ethiop J Health Sci. 2015;25(1):1-2.

8. Jember G, Melsew YA, Fisseha B, Sany K, Gelaw AY, Janakiraman B. Peripheral Sensory Neuropathy and associated factors among adult diabetes mellitus patients in Bahr Dar, Ethiopia. J Diabetes Metab Disord. 2017;16(1):16.

9. Adebamowo SN, Tekola-Ayele F, Adeyemo AA, Rotimi CN. Genomics of Cardiometabolic Disorders in SubSaharan Africa. Public Health Genomics. 2017;20(1):9-26.

10. Pastakia SD, Pekny CR, Manyara SM, Fischer L. Diabetes in sub-Saharan Africa-from policy to practice to progress: targeting the existing gaps for future care for diabetes. Diabetes Metab Syndr Obes Targets Ther. 2017;10:247.

11. Misganaw A, Mariam DH, Ali A, Araya T. Epidemiology of major non-communicable diseases in Ethiopia: a systematic review. J Health Popul Nutr. 2014;32(1):1.

12. Abda E, Hamza L, Tessema F, Cheneke W. Metabolic syndrome and associated factors among outpatients of Jimma University Teaching Hospital. Diabetes Metab Syndr Obes Targets Ther. 2016;9:47.

13. Biadgo B, Melku M, Abebe SM, Abebe M. Hematological indices and their correlation with fasting blood glucose level and anthropometric measurements in type 2 diabetes mellitus patients in Gondar, Northwest Ethiopia. Diabetes Metab Syndr Obes Targets Ther. 2016;9:91.

14. da Rocha Fernandes J, Ogurtsova K, Linnenkamp U, Guariguata L, Seuring T, Zhang P, et al. IDF Diabetes Atlas estimates of 2014 global health expenditures on diabetes. Diabetes Res Clin Pract. 2016;117:48-54.

15. International Diabetes Federation, IDF Diabetes, Atlas, 6th ed [Internet]. Available from: https://www.idf.org/elibrary/epidemiology-research/diabetes-atlas/19-atlas-6th-edition.html

16. Tesfaye F, Byass P, Wall S. Population based prevalence of high blood pressure among adults in Addis Ababa: uncovering a silent epidemic. BMC Cardiovasc Disord. 2009;9(1):39.

17. Wondemagegn AT, Bizuayehu HM, Abie DD, Ayalneh GM, Tiruye TY, Tessema MT. Undiagnosed diabetes mellitus and related factors in East Gojjam (NW Ethiopia) in 2016: a community-based study. J Public Health Res. 2017;6(1). 
18. Tesfaye T, Shikur B, Shimels T, Firdu N. Prevalence and factors associated with diabetes mellitus and impaired fasting glucose level among members of federal police commission residing in Addis Ababa, Ethiopia. BMC Endocr Disord. 2016;16(1):68.

19. Abrha S, Shiferaw S, Ahmed KY. Overweight and obesity and its socio-demographic correlates among urban Ethiopian women: evidence from the 2011 EDHS. BMC Public Health. 2016;16(1):636.

20. Fikadu G, Lemma S. Socioeconomic status and hypertension among teachers and bankers in Addis Ababa, Ethiopia. Int J Hypertens. 2016;2016.

21. Rydén L, Standl E, Bartnik M, Van den Berghe G, Betteridge J, De Boer M-J, et al. † Guidelines on diabetes, prediabetes, and cardiovascular diseases: executive summary: The Task Force on Diabetes and Cardiovascular Diseases of the European Society of Cardiology (ESC) and of the European Association for the Study of Diabetes (EASD). Eur Heart J. 2007;28(1):88-136.

22. Alberti K, Eckel RH, Grundy SM, Zimmet PZ, Cleeman JI, Donato KA, et al. Harmonizing the metabolic syndrome. Circulation. 2009;120(16):1640-5.

23. Ofori-Asenso R, Agyeman AA, Laar A, Boateng D. Overweight and obesity epidemic in Ghana-a systematic review and meta-analysis. BMC Public Health. 2016;16(1):1239.

24. Ashwell M, Gibson S. Waist-to-height ratio as an indicator of 'early health risk': simpler and more predictive than using a 'matrix'based on BMI and waist circumference. BMJ Open. 2016;6(3):e010159.

25. Abdi J, Eftekhar H, Mahmoodi M, Shojaeizade D, Sadeghi R. Lifestyle of the employees working in Hamadan public sectors: application of the trans-theoretical model. Iran Red Crescent Med J. 2015;17(2).

26. Nascente FMN, Jardim TV, Peixoto M do RG, de Souza Carneiro C, Mendonça KL, Póvoa TIR, et al. Sedentary lifestyle and its associated factors among adolescents from public and private schools of a Brazilian state capital. BMC Public Health. 2016;16(1):1177.

27. Fountaine CJ, Piacentini M, Liguori GA. Occupational sitting and physical activity among university employees. Int J Exerc Sci. 2014;7(4):295.

28. Freedman MR, Rubinstein RJ. Obesity and food choices among faculty and staff at a large urban university. J Am Coll Health. 2010;59(3):205-10.

29. Magalhães P, Capingana DP, Mill JG. Prevalence of the metabolic syndrome and determination of optimal cut-off values of waist circumference in university employees from Angola. Cardiovasc J Afr. 2014;25(1):27.

30. Organization WH. WHO STEPwise Approach to Surveillance (STEPS). STEPS Manual. Geneva World Health Organ. 2015;

31. Filippatos TD, Rizos EC, Gazi IF, Lagos K, Agouridis D, Mikhailidis DP, et al. Differences in metabolic parameters and cardiovascular risk between American Diabetes Association and World Health Organization definition of impaired fasting glucose in European Caucasian subjects: a cross-sectional study. Arch Med Sci AMS. 2013;9(5):788.

32. Belachew T. Are we ready for the rising silent epidemic of metabolic syndrome and chronic noncommunicable disease in Ethiopia? Ethiop J Health Sci. 2015;25(1):1-2.

33. Neupane S, Prakash K, Doku DT. Overweight and obesity among women: analysis of demographic and health survey data from 32 Sub-Saharan African Countries. BMC Public Health. 2015;16(1):30.

34. Obesity and overweight [Internet]. [cited 2019 May 29]. Available from: https://www.who.int/news-room/factsheets/detail/obesity-and-overweight 
35. Kengne AP, Bentham J, Zhou B, Peer N, Matsha TE, Bixby H, et al. Trends in obesity and diabetes across Africa from 1980 to 2014: an analysis of pooled population-based studies. Int J Epidemiol. 2017;

36. Okorodudu DO, Jumean MF, Montori VM, Romero-Corral A, Somers VK, Erwin PJ, et al. Diagnostic performance of body mass index to identify obesity as defined by body adiposity: a systematic review and meta-analysis. Int J Obes. 2010;34(5):791.

37. Javed A, Jumean M, Murad MH, Okorodudu D, Kumar S, Somers V, et al. Diagnostic performance of body mass index to identify obesity as defined by body adiposity in children and adolescents: a systematic review and meta-analysis. Pediatr Obes. 2015;10(3):234-44.

38. Betre M, Kebede D, Kassaye M. Modifiable risk factors for coronary heart disease among young people in Addis Ababa. East Afr Med J. 1997;74(6):376-81.

39. Zein ZA, Assefa M. Blood-pressure levels and hypertension in rural Ethiopian communities. Ethiop Med J. 1986;24(4):169.

40. Awoke A, Awoke T, Alemu S, Megabiaw B. Prevalence and associated factors of hypertension among adults in Gondar, Northwest Ethiopia: a community based cross-sectional study. BMC Cardiovasc Disord. 2012;12(1):113.

41. Tesfaye F, Byass P, Wall S. Population based prevalence of high blood pressure among adults in Addis Ababa: uncovering a silent epidemic. BMC Cardiovasc Disord. 2009;9(1):39.

42. Abebe SM, Berhane Y, Worku A, Assefa A. Diabetes mellitus in North West Ethiopia: a community based study. BMC Public Health. 2014;14(1):97.

43. Zekewos A, Loha E, Egeno T, Wubshet K, Merga Z. Prevalence of Diabetes Mellitus and Associated Factors in Southern Ethiopia: A Community Based Study. Ethiop J Health Sci. 2018;28(4).

44. Tesfaye T, Shikur B, Shimels T, Firdu N. Prevalence and factors associated with diabetes mellitus and impaired fasting glucose level among members of federal police commission residing in Addis Ababa, Ethiopia. BMC Endocr Disord. 2016;16(1):68.

45. Helelo TP, Gelaw YA, Adane AA. Prevalence and associated factors of hypertension among adults in Durame Town, Southern Ethiopia. PloS One. 2014;9(11):e112790.

46. Lam BCC, Koh GCH, Chen C, Wong MTK, Fallows SJ. Comparison of body mass index (BMI), body adiposity index (BAl), waist circumference (WC), waist-to-hip ratio (WHR) and waist-to-height ratio (WHtR) as predictors of cardiovascular disease risk factors in an adult population in Singapore. PloS One. 2015;10(4):e0122985.

47. Meme N, Amwayi S, Nganga Z, Buregyeya E. Prevalence of undiagnosed diabetes and pre-diabetes among hypertensive patients attending Kiambu district Hospital, Kenya: a cross-sectional study. Pan Afr Med J. 2015;22(1).

48. Mayega RW, Guwatudde D, Makumbi F, Nakwagala FN, Peterson S, Tomson G, et al. Diabetes and prediabetes among persons aged 35 to 60 years in eastern Uganda: prevalence and associated factors. PloS One. 2013;8(8):e72554.

49. Rahmanian K, Shojaie M. The prevalence of pre-hypertension and its association to established cardiovascular risk factors in south of Iran. BMC Res Notes. 2012;5(1):386.

50. Okwuonu CG, Ngoka SC, Chimezie OJ, Eze TH, Uwanurochi K, Mbanaso AU. Towards prevention of hypertension in Nigeria: a study of prehypertension and its associations among apparently healthy adults in Umuahia, South-East Nigeria. Int J Prev Med. 2015;6.

Page $12 / 16$ 
51. Haggblade S, Duodu KG, Kabasa JD, Minnaar A, Ojijo NK, Taylor JR. Emerging early actions to bend the curve in Sub-Saharan Africa's nutrition transition. Food Nutr Bull. 2016;37(2):219-41.

\section{Tables}

Table1. Socio demographic, anthropometric, clinical characteristic, and physical measurement of the study population stratified by gender, North West Ethiopia $(n=381)$.

\begin{tabular}{|c|c|c|c|c|}
\hline & \multirow{2}{*}{\multicolumn{2}{|c|}{$\begin{array}{c}\text { Sex } \\
\text { Mean }(95 \% \mathrm{CI}) / \mathrm{N}(\%)\end{array}$}} & \multirow{3}{*}{$\begin{array}{l}\text { Total } \\
\text { Mean (95\% CI) / N (\%) }\end{array}$} & \multirow[t]{3}{*}{ p-value ${ }^{1}$} \\
\hline & & & & \\
\hline & Male $(\mathrm{N}=330)$ & Female $(\mathrm{N}=51)$ & & \\
\hline Age (years) ${ }^{x}$ & $33.15(32.4,33.9)$ & $35.51(33.0,38.1)$ & $33.46(32.7,34.2)$ & 0.03 \\
\hline \multicolumn{5}{|l|}{ Age category $\mathrm{y}$} \\
\hline $25-35$ & $219(66.4)$ & $28(54.9)$ & $247(64.8)$ & 0.002 \\
\hline $36-45$ & $82(24.8)$ & $10(19.6)$ & $92(24.2)$ & \\
\hline $46-55$ & $29(8.8)$ & $13(25.5)$ & $42(11)$ & \\
\hline \multicolumn{5}{|l|}{ Education level ${ }^{\mathrm{y}}$} \\
\hline Under graduate & $80(24.2)$ & $14(27.5)$ & $94(24.7)$ & 0.874 \\
\hline Post graduate & $242(73.3)$ & $36(70.6)$ & $278(73)$ & \\
\hline $\mathrm{PhD}$ & $8(2.4)$ & $1(2)$ & $9(2.4)$ & \\
\hline \multicolumn{5}{|l|}{ Marital status $\mathrm{y}$} \\
\hline Married & $140(42.4)$ & $19(37.2)$ & $159(41.7)$ & 0.100 \\
\hline Single & $178(53.9)$ & $31(60.8)$ & $209(54.9)$ & \\
\hline Divorced/widowed & $12(3.7)$ & $1(2.0)$ & $13(3.4)$ & \\
\hline Height $\mathrm{cm}^{\mathrm{x}}$ & $168.2(167.7,168.7)$ & $160.1(158.5,161.8)$ & $167.1(166.5,167.8)$ & 0.00 \\
\hline Weight kg $\mathrm{x}$ & $66.2(65.3,66.5)$ & $63.4(61.1,65.5)$ & $65.8(65.0,66.5)$ & 0.02 \\
\hline $\mathrm{BMI} \mathrm{kg} / \mathrm{m}^{2} \mathrm{x}$ & $23.4(23.1,23.7)$ & $24.8(23.8,25.7)$ & $23.7(23.3,23.9)$ & 0.003 \\
\hline WC $\mathrm{cm}^{\mathrm{x}}$ & $88.2(87.4,88.9)$ & $81.9(80.3,83.5)$ & $87.4(86.6,88.1)$ & 0.000 \\
\hline WHtR $x$ & $0.52(0.51,0.52)$ & $0.51(0.50,0.52)$ & $0.51(0.50,0.52)$ & 0.074 \\
\hline WHR $x$ & $0.92(0.91,0.93)$ & $0.89(0.87,0.91)$ & $0.92(0.91,0.92)$ & 0.002 \\
\hline Pre-diabetes & $73(22.12)$ & $16(31.4)$ & $89(23.4)$ & 0.146 \\
\hline \multicolumn{5}{|l|}{ Diabetes $^{y}$} \\
\hline Known & $10(3.0)$ & $01(1.9)$ & $13(3.4)$ & \\
\hline Newly known & $05(1.5)$ & $01(1.9)$ & $05(1.3)$ & 0.841 \\
\hline Pre-hypertension & $126(38.2)$ & $24(47.1)$ & $150(39.4)$ & 0.227 \\
\hline \multicolumn{5}{|l|}{ Hypertension $\mathrm{y}$} \\
\hline Known & $21(6.4)$ & $03(5.9)$ & $24(6.3)$ & \\
\hline Newly known & 24 (7.3) & $05(9.8)$ & $29(7.6)$ & 0.694 \\
\hline
\end{tabular}

${ }^{\mathrm{x}}$ Data are expressed as mean with $95 \%$ confidence interval, ${ }^{\mathrm{Y}}$ Data are expressed as frequency with percentage. BMI - bc mass index, WC - waist circumference, WHR - waist hip ratio, WHtR - waist height ratio. ${ }^{1}$ Chi-square test for categori variables, Analysis of variance for continuous variables 
Table 2 Mean general obesity/body mass index (BMI) and the prevalence of pre-obesity $\left(25-29.9 \mathrm{~kg} / \mathrm{m}^{2}\right)$ and obesity $(\geq$ $30 \mathrm{~kg} / \mathrm{m}^{2}$ ) by gender and age, Gondar, Ethiopia

\begin{tabular}{lllllllll}
\hline \multirow{2}{*}{ Age group } & \multicolumn{3}{c}{ Men (N=330) } & \multicolumn{5}{c}{ Women (N=51) } \\
\cline { 2 - 9 } & $\mathbf{N}$ & Mean (95\%CI)* & \multicolumn{2}{c}{$\mathbf{N}(\%)$} & $\mathbf{N}$ & Mean (95\%CI) & \multicolumn{2}{c}{$\mathbf{N}(\%)$} \\
& & & Preobese & Obese & & & Preobese & Obese \\
$\mathbf{2 5 - 3 5}$ & 219 & $23.1(22.7,23.4)$ & $41(18.7)$ & $5(2.3)$ & 28 & $24.0(23.1,24.9)$ & $6(21.4)$ & $1(3.6)$ \\
$\mathbf{3 6 - 4 5}$ & 82 & $24.1(23.4,24.7)$ & $26(31.7)$ & $3(3.7)$ & 10 & $27.0(22.9,31.0)$ & $3(30)$ & $3(30)$ \\
$\mathbf{4 6 - 5 5}$ & 29 & $24.4(23.4,25.3)$ & $11(37.9)$ & $3(10.3)$ & 13 & $24.7(23.0,26.4)$ & $3(23.1)$ & $1(7.7)$ \\
Age adjusted & 330 & $23.4(23.1,23.7)$ & $78(23.6)$ & $11(3.3)$ & 51 & $24.8(23.8,25.8)$ & $12(23.5)$ & $5(9.8)$ \\
\hline
\end{tabular}

Values are presented as mean (95\% confidence interval) and frequency (percentage among each gender) adjusted for age. *Significant difference in mean BMI between age groups in men.

Table 3 Mean of measures of central obesity (CO) and the prevalence of central obesity (WC, WHtR, WHR) by age and gender, $\mathrm{N}=381(\mathrm{M}=330, \mathrm{~F}=51)$ Gondar, Ethiopia.

\begin{tabular}{|c|c|c|c|c|c|c|}
\hline \multirow{2}{*}{$\begin{array}{l}\text { Age group \& gender } \\
(\mathrm{N})\end{array}$} & \multicolumn{2}{|l|}{ WC } & \multicolumn{2}{|c|}{ WHtR } & \multicolumn{2}{|c|}{ WHR } \\
\hline & $\begin{array}{l}\text { Mean } \\
(95 \% \mathrm{CI})\end{array}$ & $\begin{array}{l}\text { CO by } \\
\text { WC N } \\
(\%)\end{array}$ & $\begin{array}{l}\text { Mean } \\
(95 \% \mathrm{CI})\end{array}$ & $\begin{array}{l}\text { CO by } \\
\text { WHtR N } \\
(\%)\end{array}$ & $\begin{array}{l}\text { Mean } \\
(95 \% \mathrm{CI})\end{array}$ & $\begin{array}{l}\text { CO by WHR N } \\
(\%)\end{array}$ \\
\hline \multicolumn{7}{|l|}{ Men } \\
\hline $25-35$ (219) & $86.8(85.9,87.7)$ & $51(23.3)$ & $0.52(.51, .52)$ & $101(46.1)$ & $0.92(.91, .93)$ & $116(53)$ \\
\hline $36-45(82)$ & $89.6(88.1,91.1)$ & 35 (42.7) & $0.53(.52, .54)$ & $52(63.4)$ & $0.94(.92, .95)$ & $57(69.5)$ \\
\hline $46-55(29)$ & $94.2(90.9,97.6)$ & 17 (58.9) & $0.56(.53, .57)$ & $23(79.3)$ & $0.96(.92, .99)$ & $21(72.4)$ \\
\hline Age adjusted & $88.2(87.4,88.9)^{*}$ & $\begin{array}{c}103 \\
(31.2)^{*}\end{array}$ & $\begin{array}{l}0.52(.51 \\
.53) *\end{array}$ & 176 (53.3)* $^{*}$ & $\begin{array}{l}0.93 \\
(.92, .94)^{*}\end{array}$ & $194(58.8)^{*}$ \\
\hline \multicolumn{7}{|l|}{ Women } \\
\hline $25-35(28)$ & $80.8(78.5,83.0)$ & $10(35.7)$ & $0.50(.49, .52)$ & $9(32.1)$ & $0.87(.85, .90)$ & $13(46.4)$ \\
\hline $36-45(10)$ & $82.6(78.2,86.9)$ & $6(60)$ & $0.51(.48, .54)$ & $5(50)$ & $0.92(.87, .97)$ & $7(70)$ \\
\hline $46-55(13)$ & $84.0(81.1,86.9)$ & $9(69.2)$ & $0.53(.51, .55)$ & $8(61.5)$ & $0.93(.88, .97)$ & $9(69.2)$ \\
\hline Age adjusted & $81.9(80.3,83.5)$ & $25(49)$ & $0.51(.50, .52)$ & $22(43.1)$ & $0.90(.88, .92)$ & $29(56.9)$ \\
\hline
\end{tabular}

'entral obesity by WC ( $\mathrm{M} \geq 94 \mathrm{~cm}, \mathrm{~F} \geq 80 \mathrm{~cm}$ ), central obesity by WHtR ( $\mathrm{M} \& \mathrm{~F} \geq 0.50$ ) and central obesity by WHR ( $\mathrm{M} \geq 1$ $i \geq 0.85$ ). Values are presented as mean (95\% confidence interval) and frequency (percentage) adjusted for age. M- mal emale, CI-confidence interval, CO-Central obesity, WC-waist circumference, WHtR- waist-to-height ratio, WHR-waist-tı atio.

ble 4 Cardio-metabolic risk factor differences based on general obesity, central obesity by WC, central obesity by WHtR an ntral obesity by WHR in academic employees University of Gondar, Ethiopia 


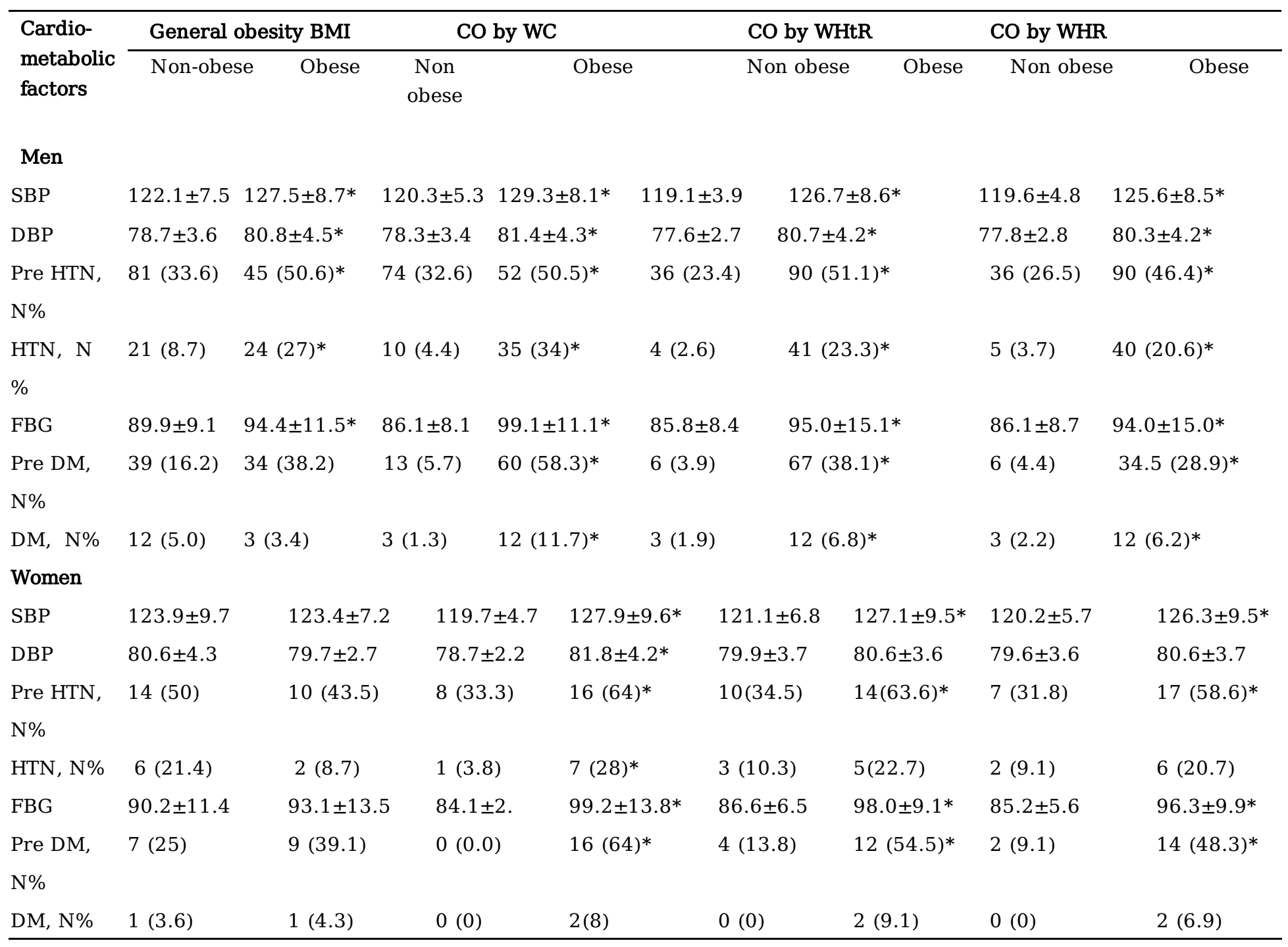

'alues are presented as mean $\pm \mathrm{SD}$ or $\mathrm{N}(\%)$ adjusted for age as indicated. $\mathrm{P}<0.05$, (Chi square for categorical and analysis ariance for continuous variable). $* \mathrm{P}<0.05$ between non-obese and obese in the same group. BMI - body mass index, WC- wa ircumference, WHtR- waist height ratio, WHR waist hip ratio, SBP systolic blood pressure, DBP diastolic blood pressure, H: ypertension, FBG fasting blood glucose.

Table 5 Correlation ( $r$ ) between cardio-metabolic risk factors with BMI, WC, WHtR, WHR and age

\begin{tabular}{lcclcc}
\hline Variables sex wise & BMI (r) & WC (r) & WHtR (r) & WHR (r) & Age (r) \\
\hline Men & & & & & \\
SBP & $.388^{* *}$ & $.608^{* *}$ & $.582^{* *}$ & $.357^{* *}$ & $.499^{* *}$ \\
DBP & $.315^{* *}$ & $.477^{* *}$ & $.452^{* *}$ & $.366^{* *}$ & $.399^{* *}$ \\
FBG & $.282^{* *}$ & $.582^{* *}$ & $.511^{* *}$ & $.314^{* *}$ & $.443^{* *}$ \\
Age & $.275^{* *}$ & .340 & $.305^{* *}$ & $185^{* *}$ & 1 \\
Women & & & & & \\
SBP & .010 & $.361^{*}$ & $.366^{*}$ & $.345^{*}$ & $.430^{* *}$ \\
DBP & .116 & $.340^{*}$ & .264 & .152 & $.323^{*}$ \\
FBG & .110 & $.656^{*}$ & $.633^{*}$ & $.547^{* *}$ & .264 \\
Age & .179 & $285^{*}$ & $278^{*}$ & $385^{* *}$ & 1 \\
\hline
\end{tabular}

Page $15 / 16$ 
** Significant at the level 0.001 (2-tailed), * Significant at the level 0.05 (2-tailed)

[able 6 Multivariate analysis adjusted Odds ratio of Pre-DM, DM, Pre-hypertension and ıypertension for general obesity and central obesity measures (WC, WHtR, WHR) among men and vomen academic employees of UOG, Ethiopia.

\begin{tabular}{|c|c|c|c|c|}
\hline & \multirow{2}{*}{$\begin{array}{c}\text { General obesity } \\
\text { BMI }\end{array}$} & \multirow{2}{*}{$\begin{array}{l}\text { Central obesity by WC } \\
\text { OR }(95 \% \mathrm{CI})\end{array}$} & \multicolumn{2}{|c|}{ Central obesity by WHtR Central obesity by WHR } \\
\hline & & & OR $(95 \% \mathrm{CI})$ & OR $(95 \% \mathrm{CI})$ \\
\hline Pre HTN & $1.14(.633,1.77)$ & $1.33(.737,2.03)$ & $2.690(1.49,4.58)^{* *}$ & $1.369(.781,2.40)$ \\
\hline HTN & $1.24(.626,2.328)$ & $5.14(2.503,9.72) * *$ & $2.066(1.008,6.31)^{*}$ & $1.119(.778,3.38)$ \\
\hline Pre DM & $1.17(.570,2.398)$ & $4.03(2.974,5.96)^{* *}$ & $1.716(.864,4.62)$ & $1.620(.956,4.68)$ \\
\hline $\mathrm{DM}$ & $1.45(.447,4.727)$ & $3.29(1.099,6.01) *$ & $1.855(.76,4.32) *$ & - \\
\hline
\end{tabular}

CI - confidence interval, $* p<0.05, * * p<0.001$, multi-variate logistic regression analysis adjusted for age. Anthropometric measures with significant OR value are in bold.

\section{Supplementary Files}

This is a list of supplementary files associated with this preprint. Click to download.

- Appendixfile1.docx 